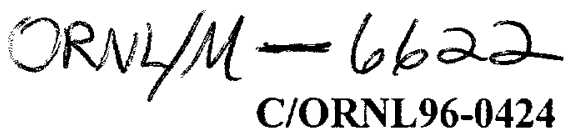

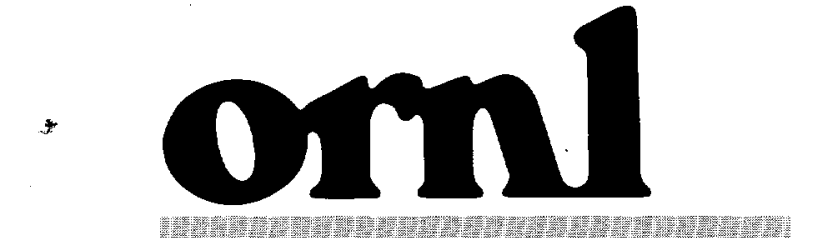

OAK RIDGE

NATIONAL

LABORATORY
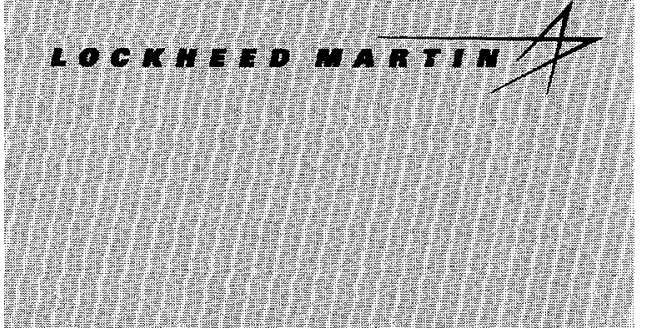

(4)

MANACED AND OPERATED BY

LOCKHEED WARTNN ENEREY AESEARCH CORPOAATION FORTHE UHTED STATES

OEPARTUENT OF ENERGY

\author{
CRADA Final Report for \\ CRADA Number ORNL96-0424 \\ ORNL/M-6622 \\ ADVANCED MICRO OPTICS \\ CHARACTERIZATION USING COMPUTER \\ GENERATED HOLOGRAMS \\ L. C. Maxey \\ Oak Ridge National Laboratory \\ P.O. Box 2008 \\ Oak Ridge, TN 37831-6004 \\ S. Arnold \\ Diffraction International \\ 11345 Hwy. 7, \#421 \\ Minneapolis, MN 55305 \\ W. Moreshead \\ J. L. Nogues \\ Geltech, Inc. \\ 3267 Progress Dr., Suite B \\ Orlando, FL 32826 \\ RECEIVED \\ DEC 161998 \\ OSTI
}

\author{
Prepared by the \\ Oak Ridge National Laboratory \\ Oak Ridge, Tennessee 37831-6285 \\ managed by \\ Lockheed Martin Energy Research \\ for the \\ U. S. Department of Energy \\ under contract DE-AC05-96OR22400
}

Approved for Public Release; distribution is unlimited. 
This report has been reproduced directly from the best available copy.

Available to DOE and DOE contractors from the Office of Scientific and Technical Information, P.O. Box 62, Oak Ridge, TN 37831; prices available from (423) 576-8401, FTS 626-8401.

Available to the public from the National Technical Information Service, U.S. Department of Commerce, 5285 Port Royal Rd., Springfield, VA 22161.

NTIS price codes-Printed Copy: A03 Microfiche A01

This report was prepared as an account of work sponsored by an agency of the United States Government. Neither the United States Government nor any agency thereof, nor any of their employees, makes any warranty, express or implied, or assumes any legal liability or responsibility for the accuracy, completeness, or usefulness of any information, apparatus, product, or process disclosed, or represents that its use would not infringe privately owned rights. Reference herein to any specific commercial product, process, or service by trade name, trademark, manufacturer, or otherwise, does not necessarily constitute or imply its endorsement, recommendation, or favoring by the United States Government or any agency thereof. The views and opinions of authors expressed herein do not necessarily state or reflect those of the United States Government or any agency thereof. 


\section{DISCLAIMER}

Portions of this document may be illegible in electronic image products. Images are produced from the best available original document. 
Instrumentation and Controls Division

\title{
ADVANCED MICRO OPTICS CHARACTERIZATION USING COMPUTER GENERATED HOLOGRAMS
}

\author{
Curt Maxey \\ Oak Ridge National Laboratory \\ Steve Arnold \\ Diffraction International \\ Jean-Luc Nogues \\ Bill Moreshead \\ Geltech, Inc.
}

This report was developed under DOE CRADA No. ORNL96-0424.

This work was supported through a CRADA with Geltech, Inc., Orlando, Florida and Diffraction International, Minneapolis, Minnesota sponsored by the Laboratory Technology Research Program, Office of Energy Research, U.S. Department of Energy, under contract DE-AC05-96OR22464 with Oak Ridge National Laboratory, managed by Lockheed Martin Energy Research Corporation. 


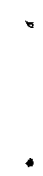




\section{CONTENTS}

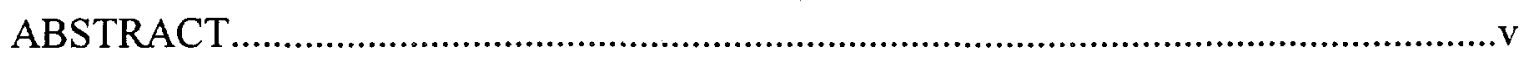

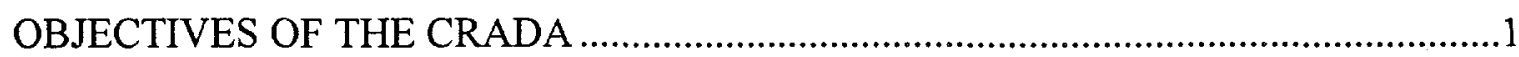

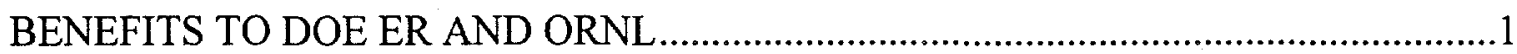

TECHNICAL DISCUSSION OF WORK ACCOMPLISHED ………...............................

INTELLECTUAL PROPERTY CONSIDERATIONS....................................................

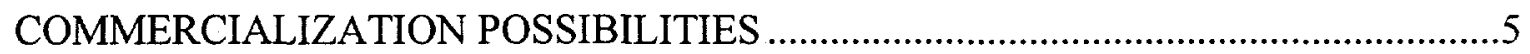

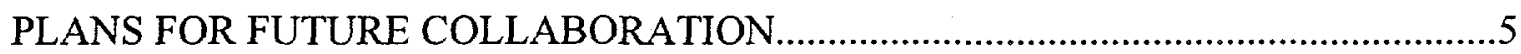

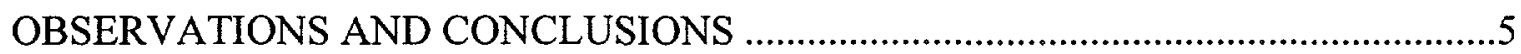

APPENDIX A: Affordable Aspheric Testing Technology Comes to Light .........................7

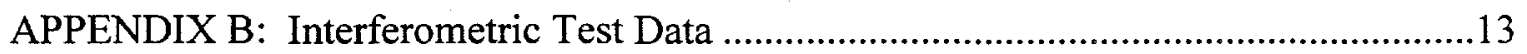




\begin{abstract}
This CRADA provided the opportunity to combine the resources of a National Laboratory, a university sponsored Center for Optics Manufacturing, and two innovative small businesses to address an emerging need in the testing of optical components. Oak Ridge National Laboratory, the University of Rochester Center for Optics Manufacturing (COM), Diffraction International Ltd., and Geltech Inc. combined efforts to address the use of Computer Generated Holograms for testing micro optics.
\end{abstract}

As the demand for smaller and lighter optical systems continues to push the manufacturing capabilities for producing the necessary optical elements, a concurrent challenge arises in the ability to test those elements. Modern high performance optical systems rely heavily on the use of aspheric surfaces to achieve maximum performance with the fewest optical elements. Conventional lenses are composed of polished spherical surfaces and have been the backbone of the optics industry since its inception. Aspheric surfaces, traditionally used in telescope designs, have begun to proliferate in designs for all types of systems during the last decade. Testing these surfaces has been a tremendous challenge because conventional interferometers for testing spherical surfaces are difficult to adapt to the testing of aspheres.

Computer Generated Holograms (CGHs) have been the most significant technology breakthrough in the testing of aspheric optics. CGHs were used to certify the corrective optics for the Hubble Space Telescope (HST), replacing the earlier technology of conventional null lenses (like the one that led to the unfortunate error in the HST primary mirror). Although CGHs have been used to a limited degree for almost 20 years, they were first commercialized in a form useful to the optics testing industry by Diffraction International through an earlier CRADA with ORNL (see CRADA Final Report ORNL93-0218). In that CRADA, the optics tested ranged from $5 \mathrm{~cm}$ to $20 \mathrm{~cm}$ in diameter. Additional information on $\mathrm{CGH}$ testing is presented in Appendix A.

Micro optical elements (with diameters of a few millimeters or less) make possible many of the systems required in the communications, medical, and other leading edge industries. Reliably producing glass micro optics with aspheric surfaces is, however, an emerging technology area. Geltech Inc. has pioneered this technology with their press molded optics (PMO lenses) that replicate diamond turned aspheric surfaces in glass substrates. COM has been the vanguard force in the development of microgrinding technology, which they are now applying to the production of aspheric glass optics (including micro optics). The lack of reliable testing technology for aspheric micro optics limits the mastery of the manufacturing processes for them.

This CRADA has enabled the validation of CGH testing for certain classes of micro optics. It has also identified certain issues that are significant when considering the use of CGHs in this application. Both contributions are advantageous in the pursuit of better manufacturing and testing technologies for these important optical components. 


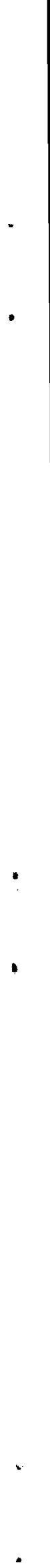




\section{OBJECTIVES OF THE CRADA}

The objectives of this CRADA were to extend the application of CGH testing technology to micro optical surfaces and components. In the course of applying CGHs to these optics the objective was to identify challenges unique to micro optics so that they may be at least recognized in advance even if their impact cannot be entirely avoided or resolved.

\section{BENEFITS TO DOE ER AND ORNL}

The extension of CGH technology to the testing of certain classes of micro optical components, validated through this CRADA, will enable improvements in manufacturing technologies for production of micro optical components demanded by today's technology growth areas. The net result will be better systems at lowered manufacturing costs.

Driven by the demand for smaller high-performance optical systems in applications as diverse as optical storage, environmental monitoring and medical imaging, the proliferation of micro optical system designs is increasing. Novel methods for manufacturing or using micro optical elements require the ability to test and align them with high accuracy. Conventional measurement systems are not intrinsically suited to these tasks. This CRADA has enabled the demonstration of micro optics testing using conventional test equipment combined with $\mathrm{CGH}$ technology. As a result, emerging DOE programs that may involve manufacturing or incorporating micro optics will find the testing technology available within the organization.

\section{TECHNICAL DISCUSSION OF WORK ACCOMPLISHED}

Closely following the task statements in the SOW, the CRADA enabled the demonstration of advanced micro optics testing using a conventional interferometer with a CGH. The type of optics to be tested and testing philosophy were jointly determined during Task 1. It was determined that the two optics to be tested would both be taken from the commercial line of PMO replicated lenses manufactured by Geltech. The clear aperture sizes of the micro optics were selected with one being $5.5 \mathrm{~mm}$ in diameter and the other $1.6 \mathrm{~mm}$ in diameter (Geltech PMO part no's 350220 and 350140). The aspheric departure of the first lens was only 6 waves but the more challenging smaller lens had a departure of almost 20 waves.

Further communication among the CRADA partners led to the development of the testing configurations and the requirements for the production of test specimens (Task 2). It was agreed that the CGHs would be designed to test the convex asphere to determine its surface quality. These results were to be compared to the results of a throughput test of the optic, in which the un-modified interferometer would be used to test the lens by 
collimation and reflection from a plano mirror. It was agreed that Geltech would provide test specimens of both uncoated and anti-reflective coated surfaces for these tests.

During Task 2, discussions regarding COM's testing of the aspheric micro optics were finalized. A site visit to COM enabled extensive overview of their facilities and discussions with their metrologists. Regrettably, COM was forced to withdraw from the CRADA before the tests could begin, due to funding cutbacks. Their expertise in the early discussions during Tasks 1 and 2 were, however, of great value. The technical impact of not having the profilometry data from COM was considered inconvenient but not insurmountable.

During Task 3, fixturing hardware for the micro optics was developed and the CGHs for the two micro lenses were manufactured. This hardware was designed to securely hold the lens without obscuring the aperture and to provide five degrees of freedom with minimal crosstalk between the axes. The CGH for the first optic was designed for use with an $f / 1.5$ transmission sphere, while the second optic was designed for use with an f/ 0.75 transmission sphere. It was anticipated that we would be able to borrow or rent an f/ 0.75 transmission sphere for the tests since one was not immediately available to ORNL.

Testing of the optics was performed during Task 4. The first optic (350220) performed well with all tests and provided good visibility when tested with the CGH. The second optic (350140), however, being much thinner presented a serious problem with testing due to unwanted secondary or "ghost" fringes. Attempts were made to eliminate these fringes using an index matching fluid but were not successful. Ultimately an alternate approach was agreed upon by the three remaining CRADA partners to provide a useful test for this optic by measuring its mold pin.

The PMO optical components, including the 350140 optic, are replicated from a diamond turned surface on a mold pin. To achieve a useful result for this optic during the CRADA activities, Diffraction International Ltd. and Geltech Inc. agreed to exceed their original commitments. Diffraction International agreed to produced an additional $\mathrm{CGH}$ that was designed to test the mold pin. Geltech agreed to remove the mold pin from their processes long enough to permit measurements of the surface. Through this approach the replication surface for the optic was able to be tested. The tests at ORNL were performed with an $\mathrm{f} / 1.5$ diverger, testing approximately half of the diameter of the pin. Subsequent tests were provided by Diffraction International with an $f / 0.75$ diverger.

\section{Discussion Of Results}

The photographic data obtained during the ORNL semi-diameter testing of the mold pin for the 350140 optic provide the clearest picture of the CGH performance in testing a micro optic. Figure 1 shows the strongly curved aspheric fringes typical of an uncorrected aspheric surface tested with a conventional interferometer. The Figure 2 shows the same optic tested with the same interferometer, but with the CGH null optic 
providing the necessary correction to achieve straight fringes characteristic of a nearperfect surface. These semi-diameter photographs show only a portion of the optical surface, and represent a test of an optical surface less than a millimeter in diameter, clearly illustrating the role that the CGH performs in testing an aspheric micro-optic.

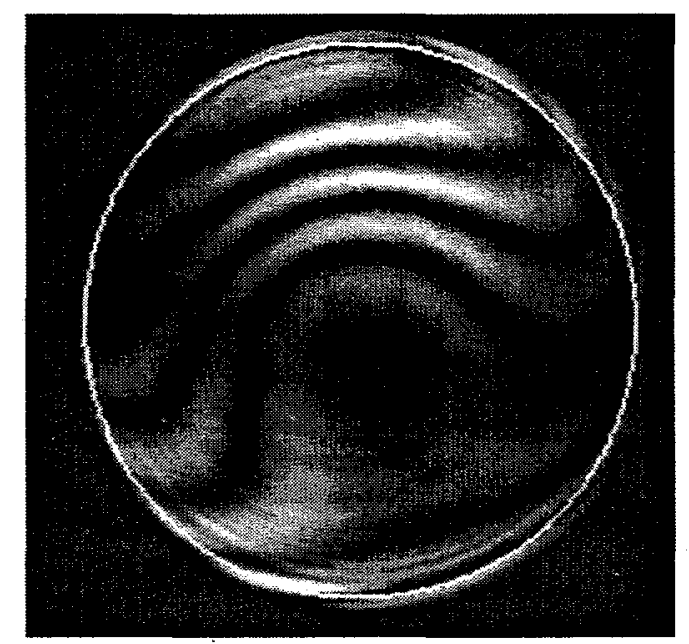

Figure 1. Interferogram of uncorrected mold pin semi-diameter, revealing spherical aberration characteristic of aspheric surfaces

In Figure 2, a discerning eye may be able to recognize a line passing near the center of the image in which the fringe quality is reduced. This was determined to be due to a coating irregularity on the optic and created significant problems for the computer analysis of the data. The interferometer at ORNL was not capable of rejecting the phase discontinuity created by this coating and could not quantitatively determine the quality of the semi-diameter surface.

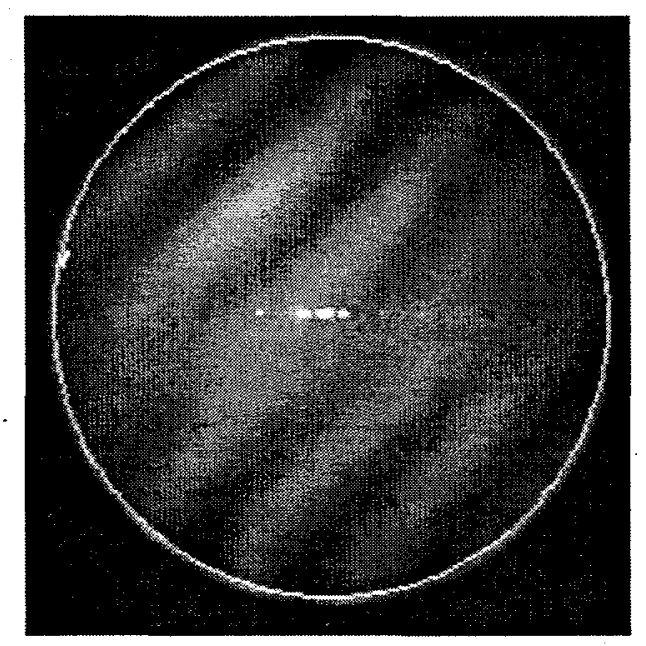

Figure 2. CGH corrected interferogram of mold pin semi-diameter showing straight fringes characteristic of an ideal surface 
Subsequent full aperture testing of the mold pin at Diffraction International was conducted with more complete results. Representative data from these tests are included in Appendix B. These full-aperture data show the CGH corrected surface and reveal errors that were not visible in the semi-diameter data. In addition, both the modulation map and the Frame 1 map show the region of poor fringe modulation (now visible as an arc rather than a line) due to coating irregularity. This complicates the direct interpretation of the data, requiring some additional computer analysis to aid in the process.

At the top of the data the peak to valley surface error is given as 1.28 fringes (PV $1.283 \mathrm{fr}$ ) but much of this is due to the modulation error. A subsequent analysis with all of the Seidel aberrations (the smoothly varying curvatures that dominate the optical performance) removed, revealed the peak to valley error to be about 0.8 fringes. This means that only about 0.5 fringes of error are due to the Seidel characterized aberrations. With one fringe being equal to one-half wavelength of the light from the interferometer, the surface can be described as near 0.25 waves of departure from the ideal surface. The aberrations in this surface will not map one-for-one into the wavefront developed by the lens, but will be a function of the refractive index of the lens material. The relationship is given by the refractive index minus one. For the PMO lenses, the refractive index is 1.6 so one could expect the final lens to have a wavefront aberration of $\{(1.6-1) \times 0.25$ waves $\}$ or 0.15 waves of aberration. This is well within the diffraction limit of 0.25 waves.

Also in Appendix B are the test results from the 350220 optic. This optic was first tested for its transmitted wavefront quality. Subsequently, the aspheric surface of the optic was tested using the CGH. The graphical data from the ORNL interferometer is presented for both tests.

The transmitted wavefront test shows a peak to valley error of about 0.08 waves, whereas the CGH test shows an error in the aspheric surface of about 0.21 waves. Based on the effect of refractive index that was just described, the wavefront would be expected to have an error of $\{(1.6-1) \times 0.21$ waves $\}$ or about 0.12 waves. The discrepancy is believed to be due to a small amount of residual alignment error resulting in some astigmatism in the test. Comparison of the Profile Plots in the two sets of data reveals the same qualitative surface characteristics, particularly with respect to the features near the center of the optic. The Filled Plots each reveal increased error near the edge of the optic, though the astigmatism in the CGH test data obscures part of this edge effect. Additional alignment effort would, perhaps, have eliminated the residual astigmatism. However, the CGH test was indicates that the surface of the optic was sufficient to produce no worse than 0.21 waves of departure that would ensure diffraction limited performance in the transmitted wavefront. 


\section{INTELLECTUAL PROPERTY CONSIDERATIONS}

No intellectual property was developed or disclosed in the course of this CRADA.

\section{COMMERCIALIZATION POSSIBILITIES}

The CGH Null Adapter, manufactured by Diffraction International Ltd., was commercialized with the aid of a previous CRADA. The micro optics experience enables additional markets for the technology to become more accessible to Diffraction International.

Geltech Inc. has a leadership role in the manufacture of glass aspheric micro optics. They have very successfully commercial several PMO lens products. Improved testing methods enable them to further ensure and increase their manufacturing capacity and product quality.

\section{PLANS FOR FUTURE COLLABORATION}

Both Diffraction International Ltd. and Geltech Inc. are long standing ORNL collaborators. The technologies that both companies represent are very well developed and are of interest in a number of emerging areas. There are no immediate plans for additional collaboration in the optical testing area but other collaborative possibilities are under casual discussion. There is potential for additional collaboration between these two industrial partners. In addition, Geltech is in partnership with ORNL in an additional CRADA in the optics manufacturing area.

\section{OBSERVATIONS AND CONCLUSIONS}

The small size and steep surface curvatures of micro optics resulted in one consideration that was of much greater significance than anticipated. Whereas with large optics the choice of a suitable interferometer configuration is usually rather flexible, micro optics (particularly when used with CGHs) are more demanding. The micro optic must be placed within the converging beam from the interferometer and the CGH must be placed between the micro optic and the output lens (or "diverger") of the interferometer. In the case of the 350140 optic there was only one suitable choice for a diverger that would allow the components to be physically assembled for the test without compromising the amount of the surface that could be measured.

The agreement between the transmitted wavefront test and the CGH surface test of the 350220 optic was very encouraging. A more complete treatment of the test results might have been possible if COM had not been forced to withdraw from the CRADA. Ideally, profilometric data could be taken from a lens surface, compared with the interferometric measurement of the surface and incorporated into an optics raytracing model for prediction of and comparison with the transmitted wavefront. 
The application of CGH testing technology to micro optics appears to be very achievable for optics whose design does not favor the incidence of "ghost fringes." This can be determined through raytracing models in most cases. The significance of "ghost fringes" was an anticipated problem but efforts to reduce the impact of these fringes were less successful than had been hoped. This represents an area for additional consideration and work beyond the scope of this CRADA.

For reflective micro optics, like the mold pin, CGHs appear to be very well suited. This is of direct significance to the manufacture of PMO lenses from diamond turned molds but may have indirect significance to other applications as well. If a particular lens is subject to formation of "ghost fringes" it may be possible to test its surfaces indirectly by forming a reflective replica from the lens itself. The physical dimensions are small enough in micro optics to limit the influence of some of the distorting influences that complicate the replication of larger optical surfaces. 


\section{APPENDIX A: Affordable Aspheric Testing Technology Comes to Light}

Background information on aspheric optics, CGH testing, and the CGH Null Adapter that was commercialized through CRADA No. 93-0218 with Diffraction International 


\title{
Affordable Aspheric Testing Technology \\ Comes to Light
}

\author{
L. Curt Maxey \\ Oak Ridge National Laboratory
}

\section{Optical systems with the best performance in the smallest, lightest packages require the use of aspheric elements}

Throughout history, testing technology has limited the production of aspheric optics

The Hubble Space Telescope misfortune graphically revealed the limitations of conventional tests based on null lenses
Better, smaller, lighter are popular adjectives of progress that are pushing state-of-the-art optical systems away from the use of spherical surfaces. Optical systems use lenses and mirrors with spherical surfaces whenever possible, because spheres are relatively easy to manufacture and test. To get the best performance, using spherical surfaces alone, requires numerous optical elements. Using aspheric components significantly reduces the number of elements required. Optimum performance in the smallest, lightest package is only achieved by including aspheric components in system designs.

Aspheric optical components were first used in astronomical telescopes. Early astronomers produced parabolic mirrors for their Newtonian telescopes by first rubbing together two round flat glass disks to produce spherical surfaces. The astronomers then meticulously hand-polished one of the resulting mirror blanks to change its shape from a sphere to a paraboloid. Changes to the mirror shape were made on the basis of the images of the stars seen through the telescope. The astronomers' capacity for interpreting the images of stars determined the quality of the mirrors they produced. Then, as now, testing technology posed the greatest limitation to the production of quality aspheric optics.

Modern optical designs contain aspheric surfaces with submicron tolerances. Although some of these optics are still produced by hand polishing, computer-controlled manufacturing is improving quality and speeding production. A few manufacturers have proprietary computer-controlled polishing processes for producing aspheric optics in glass and other brittle materials. Single point diamond turning is now routinely used to rapidly produce precision aspheric optics in metals, plastics, and selected crystalline materials.

Testing technology has not kept pace with the advances in aspheric manufacturing processes. Most precision optics are tested with laser interferometers that approach nanometer resolution but are specifically designed to measure spheres. To measure aspheres, special "null lenses" are constructed using spherical optics. Null lenses are designed to bend the light from the interferometer into a shape that matches the aspheric optic. The misfortunes of the Hubble Space Telescope graphically demonstrate the limitations of conventional null lenses. 
Whenever optical metrologists build null lenses, their skill and attention to detail are the only deterrents to disaster

The computergenerated hologram, or CGH, is a significant advance in aspheric testing and was used to test the corrective optics for the Hubble Space Telescope

CGH's are produced with computerized reliability and repeatability
The accuracy of a null lens is highly dependent on the spacing of individual lens elements. Each time a null lens is constructed by an optical metrologist, skill and attention become the only deterrents to disaster. If an error in assembly occurs, it cannot be detected without constructing another null lens to corroborate the first test. Even then, costly corroborative tests do not guarantee quality.

In the case of the Hubble Space Telescope, the primary mirror was tested with two different null lenses. When the results did not agree, the lens with the more complex design was believed to be more accurate and was used for the final manufacturing processes. There was no way to know that the lens had been assembled with a small error in spacing. The result, now well known, was a large expensive mirror precisely manufactured to the wrong shape and deployed into space before the error was detected. Ultimately, a space mission was required to install expensive corrective (aspheric) optics.

Although it has only recently been commercialized, a significant advance in aspheric metrology was developed in the early '70s. Computer-aided design and computer-controlled manufacturing were combined to produce a new type of null lens known as a computergenerated hologram (CGH). Using diffraction, the phenomenon that produces the rainbow of color in a compact disk, the CGH bends light to match the shape of a specific aspheric optic.

Before being deployed in space, the corrective optics for the Hubble Space Telescope were certified using CGHs. A more assertive testimonial to the $\mathrm{CGH}$ technology would be difficult to conceive.

The advantage of using a computer-generated hologram for aspheric testing is that the design and manufacturing processes are highly repeatable. Once characterized, they can be trusted to produce reliable CGHs again and again. The repeatability of computerized design and manufacturing processes replaces the uncertainty inherent in the manual assembly and alignment of lens elements.

Despite their significant advantages, CGHs have remained a novelty item for the optical manufacturing industry as a whole. Designing or modifying optical interferometers to incorporate $\mathrm{CGH}$ correctors is difficult and expensive. A very few organizations have had the technical and financial wherewithal to successfully implement $\mathrm{CGH}$ testing. For the rest of the industry, however, the technology has been inaccessible. The design, production, and integration of $\mathrm{CGH}$ correctors requires uncommon levels of technical expertise and financial resolve. 
Until now, few organizations have had the technical expertise and financial resolve to enjoy the advantages of CGH technology

The CGH Null Adapter places CGH technology within the reach of all aspheric optics manufacturers
True commercialization of CGH testing technology did not occur until 1992, when APA Optics marketed the Interferometer for Aspheric Testing. For the first time, optical test equipment was offered to industry with an integrated $\mathrm{CGH}$ interface. The product has not been a commercial success, despite strong industrial interest in the technology. The offering price of well over $\$ 100,000$ and the lack of clearly established technical success have significantly depressed the potential market.

The most recent commercialization of CGH testing technology offers availability, affordability, and compatibility. The CGH Null Adapter, recently marketed by Diffraction International, Ltd. places $\mathrm{CGH}$ technology within the reach of all aspheric optics manufacturers. The hardware is available at a very low cost and is designed for use with the existing test equipment common to most optics shops.

Total hardware costs to test a typical asphere with the CGH Null Adapter are about $\$ 5,000$. Additional custom holograms for testing other conventional aspheres can be purchased for around $\$ 3,500$. Even exotic aspheric optics, with unusual shapes and steep surfaces, can be tested by using more elaborate CGH correctors. These are produced through more complex manufacturing processes and are available at about two to four times the cost of the standard holograms.

Custom CGHs are now more affordable and available than conventional null lenses. CGH technology eliminates the need for expensive and obscure glass types. Computerized control provides enhanced reliability and enables automated production. The tireless reliability of electron beam lithography replaces the labor-intensive grinding, polishing and alignment of conventional null lens elements. Custom CGHs are available from Diffraction International in two to four weeks.

For the first time in optics manufacturing history, solutions to the most common aspheric measurement problems are deliverable in less than a month for about $\$ 5,000$. The technology that ensured the successful correction of the Hubble Space Telescope is now within the reach of all optics manufacturers. 


\section{APPENDIX B: Interferometric Test Data}

Full Aperture Test of Mold Pin for 350140, p. 15.

Transmitted Wavefront Test of 350220 Optic, p. 16.

CGH Corrected Test of Aspheric Surface on 350220 Optic, p. 17. 


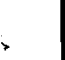

1 


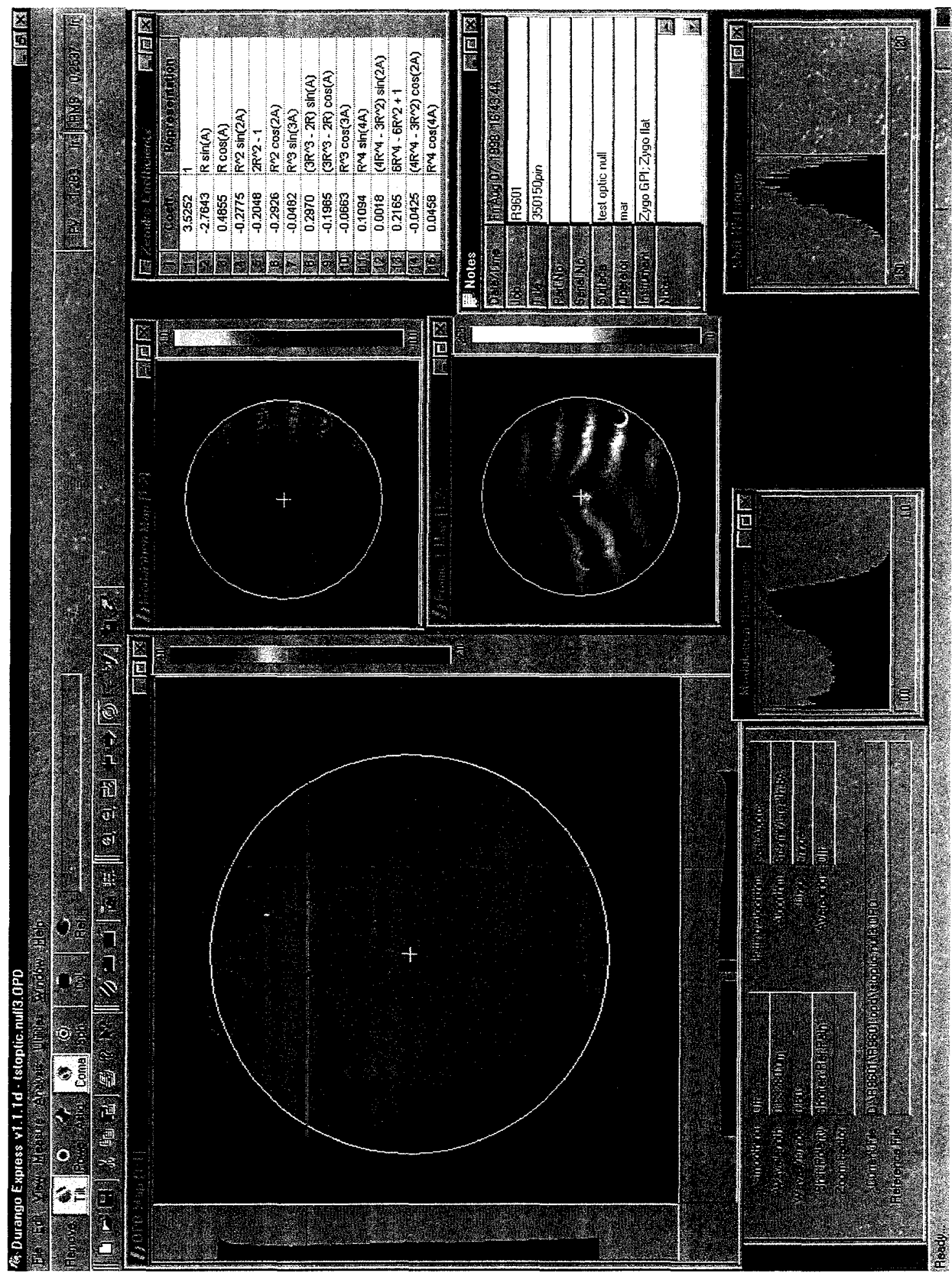




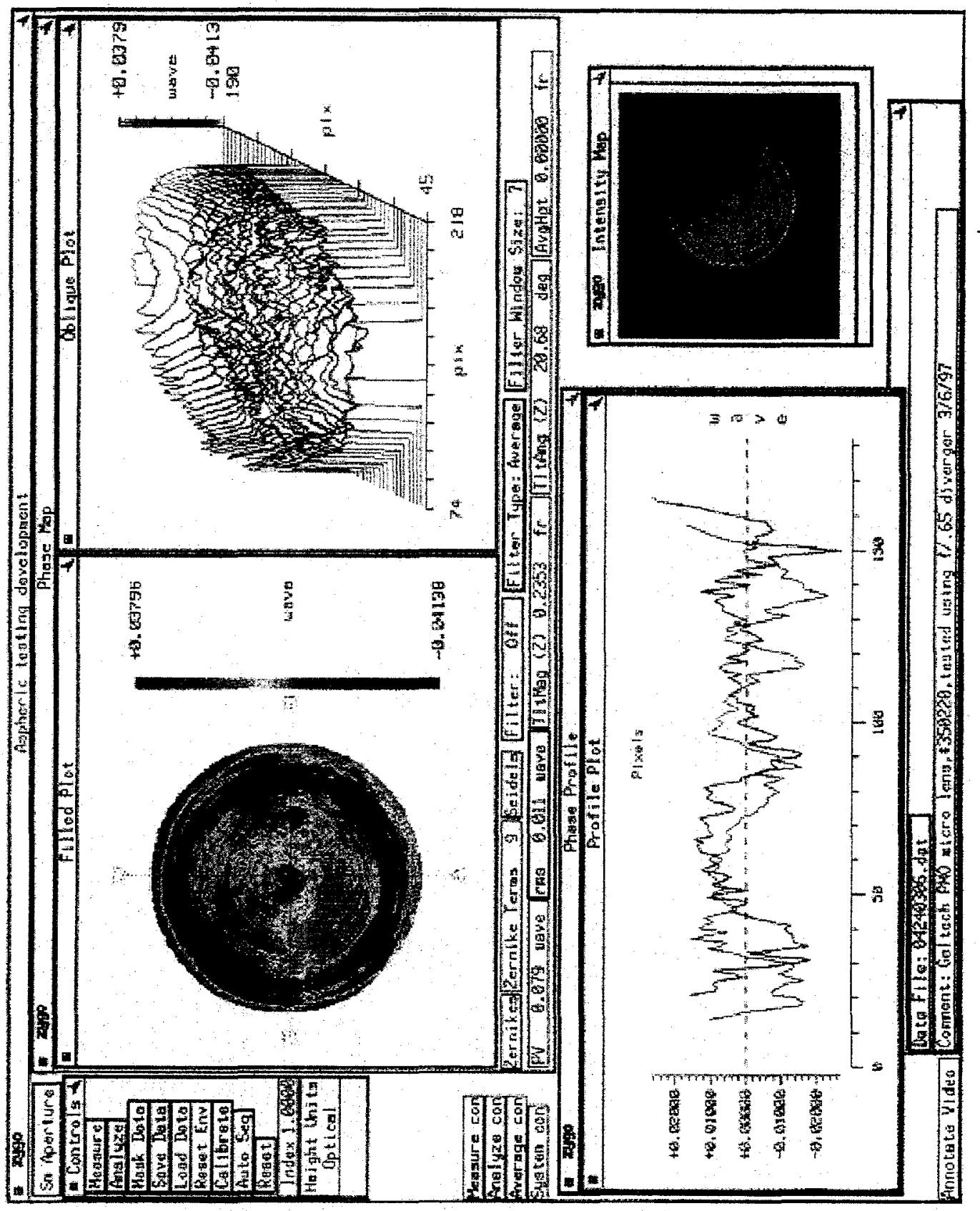




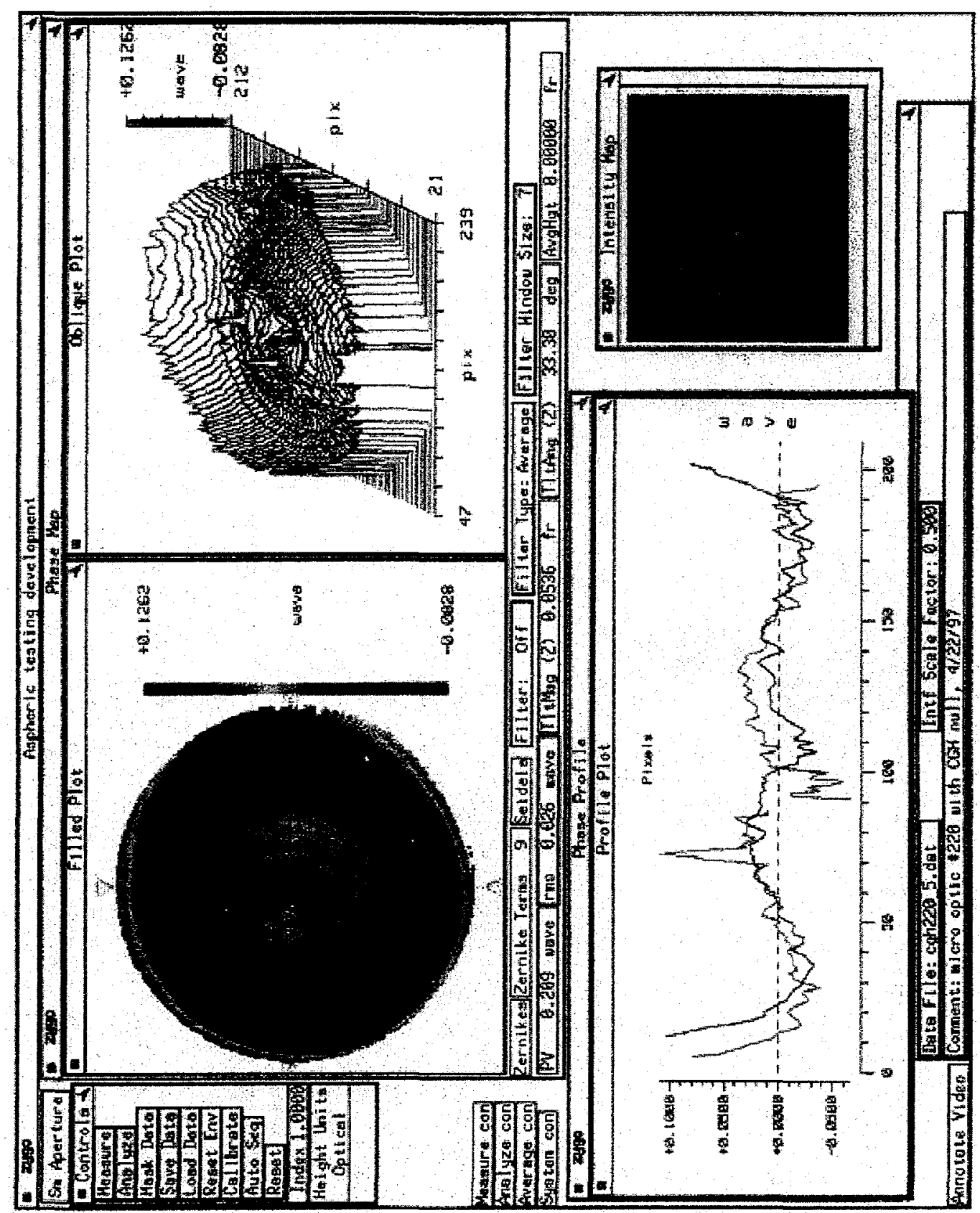


C/ORNL96-0424

\section{INTERNAL DISTRIBUTION}

1. B. B. Bovee, 701SCA, MS-8242

2. L. B. Dunlap, 5002 , MS-6014

3. R. G. Gilliland, $4500 \mathrm{~N}, \mathrm{MS}-6248$

4. P. L. Gorman, ORNL Site Office, $4500 \mathrm{~N}, \mathrm{MS}-6269$

5. B. S. Hoffheins, 3500 , MS-6004

6. A. J. Luffman, Office of Science Technology Partnerships, 5002, MS-6416

7-9. L. C. Maxey, 3500 , MS-6004

10. D. W. McDonald, 3500, MS-6005

11. K. A. Moore, 3500 , MS-6004

12. T. L. Payne, 5002, MS-6416

13. J. E. Rogers, K-1030, MS-7312

14. J. W. Shepherd, 5002, MS-6416

15. C. A. Valentine, Office of Technology Transfer Business Office, 701SCA, MS-8242

16. J. D. White, 3500 , MS-6004

17. DOE-WFO, MS-G209

18. Laboratory Records-RC (D. R. Hamrin, 4500N, MS-6285)

\section{EXTERNAL DISTRIBUTION}

19. S. Arnold, Diffraction International, 11345 Hwy. 7, \#421, Minneapolis, MN 55305

20. Dr. Sam Barish, Task Manager, Laboratory Technology Research Program, ER32, Room E-224, Department of Energy, 19901 Germantown Road, Germantown, MD 20874-1290

21. W. Moreshead, Geltech, Inc., 3267 Progress Dr., Suite B, Orlando, FL 32826

22. J. L. Nogues, Geltech, Inc., 3267 Progress Dr., Suite B, Orlando, FL 32826

23-24. Office of Scientific and Technical Information, P.O. Box 62, Oak Ridge, TN 37831 